\title{
An Estimation of an Old Age Mortality Rate Using CK Model and Relational Model
}

\author{
Kyunam Jung ${ }^{a}$, Donguk Kim ${ }^{1, a}$ \\ ${ }^{a}$ Department of Statistics, Sungkyunkwan University
}

\begin{abstract}
Due to a rapidly aging society, the future Korea mortality rate is important for planning national financial strategies and social security policies. Old age mortality statistics are very limited in their ability to project a future mortality rate; therefore, it is essential to accurately estimate the old age mortality rate. In this paper, we show that the CK model with a Relational model as a base model provides accurate estimates of old age mortality rates.
\end{abstract}

Keywords: CK model, relational model, force of mortality, life expectancy.

\section{1. 서론}

전 세계적으로 사망력 감소와 고령화가 진행되면서 인구구조가 변하고 있고, 이에 따라 기대수명 산출을 위한 고연령층의 장래 사망력은 중요한 이슈로 부각되고 있다. 장래 사망력 예측의 정확성을 높이기 위해서는 고연령층에 대한 사망력 자료의 신뢰도가 무엇보다도 중요하다. 그러나 우리나라 고 연령 사망자료는 시계열이 짧고, 고연령층에 대한 자료가 부족하여 장래 사망력 추계를 위해서는 고연 령 사망력 추정이 우선되어야 하고, 이를 위한 적절한 모형을 찾는 연구가 선행되어야 한다.

고연령 사망력에 대한 대부분의 논의는 시간이 흐름에 따라 특정연령층 사망력의 연령 추세와 패턴 에 대하여 주로 논의가 되었다. 연령별 사망률은 시간이 지나면서 감소하였고, 특히 현재 고연령 선진 국에서 실증적으로 측정될 수 있는 가장 고연령층인 100 세 이상에서도 동일하다. 그러나 고연령층 사 망력의 연령패턴에 대해서는 다양한 의견이 있다. 많은 연구에서 제시한 사망력의 연령패턴을 다음과 같이 3 가지 측면으로 나누어서 살펴보기로 한다.

첫째, 수리적 함수로서 특정연령 사망률은 연령의 함수로 표현하였다. 여기에는 Gompertz모형, Makeham모형, Perks모형, Beard모형, Heligman과 Pollard모형 등 사망력의 연령패턴을 수리적으로 나 타내는 시도가 오랫동안 지속되어 왔다. 이러한 함수 중에서 가장 오래되고 기초가 되는 하나는 Gompertz (1825)에 의해 발견된 “사망력 법칙(law of mortality)"이다. 그 법칙은 여러 연령대에 걸쳐서 훌 륭한 근사값을 주었으나 최근 고연령 선진국의 사례를 보면 고연령에 경우 그 법칙은 잘 적용되지 않 아, 여러 개의 다른 공식과 모형들이 많은 연구에 의해 제시되었다. 이러한 모형들의 상대적인 장점은 평가하기가 어려움이 있다. 왜냐하면 주로 고연령층의 신뢰할 수 있는 자료가 부족한 시점에서 연구가 이루어졌기 때문이다.

둘째는 모형 생명표 체계(model life table system)로서, 많은 유형의 인구자료를 토대로 서로 다 른 사망력 수준별로 표준화된 특정연령 사망력 패턴을 작성한 것이다. 대표적인 모형 생명표 체계는

\footnotetext{
${ }^{1}$ Corresponding author: Professor, Department of Statistics, Sungkyunkwan University, Seoul 110-745, Korea.

E-mail: dkim@skku.edu
} 
Coale과 Demeny (1966), United Nations (1982), Coale과 Guo (1989) 등에 의해 작성되었다. 이러한 모 형 생명표는 미래에 있어서 모든 국가들이 고연령국가로 전환될 것으로 보여 사망력이나 변화패턴은 궁극적으로 하나 또는 매우 적은 수의 특성패턴에 수렴하거나 근본적인 변화가 지속될 것 여부와 관련 된다. Coale과 Guo (1989)에서는 세계적인 사망력패턴은 Coale-Demeny 시스템에서 제시한 여러 가지 형태의 모형 중에서 North model과 비슷한 패턴에 수렴할 수 있다고 제시하고 있다.

셋째는 관계형 모형으로서 사망력과 연령의 기본적인 관계는 경험적으로 모형 생명표와 같이 해당 하는 값들을 제표형식으로 나타내는 것이다. 실질 개별 인구의 사망력은 표준 사망력의 수학적 변환을 통하여 모형화된다. 관계형 모형은 매우 간단(parsimonious)하다는 특징이 있는데, 사망력의 연령패턴 의 특별한 특징은 수학적 방정식의 많은 모수에서 보다는 경험적인 표준 사망표에서 포착된다는 것이 다. 추가로 관계형 모형은 유일한 제표 함수(tabulated function)만을 요구하지 모형 사망표체계에 의해 요구되는 장기 시계열을 요구하는 것은 아니다. Brass (1971)는 사망력 분석을 위하여 관계형 모형을 도입하였다.

본 연구는 기존연구인 Kim 등 (2011)과 Baek과 Jeong (2012)에서와 같은 여러 수리적 모형 비교 또 는 방법 비교와는 달리, 우리나라의 고연령층 사망력에 대한 짧은 시계열자료와 사망률의 로그증가율 추세 변화 등 연령별 경험적 특징 등을 최대한 고려할 수 있는 모형으로 Coale과 Guo (1989)에서 처음 제시된 Coale과 Kisher(CK)모형과 관계형 모형(Relational model)을 결합하여 우리나라의 장래 사망력 추계를 위한 고연령 사망력 추정에 목적이 있다.

먼저, 제 2장에서는 고연령 사망력 추정에 사용할 수 있는 CK모형과 관계형 모형의 특징을 살펴보 고, 제 3장에서는 우리나라 사망력자료의 CK모형 적합성을 살펴본 후, $\mathrm{CK}$ 모형을 통하여 연령별 표준 사망력을 추정하고, 관계형 모형을 통하여 과거 고연령부분에 대한 사망력자료를 연장하고 기대수명 을 산출한다. 마지막으로 제 4장에서는 향후 제언을 제시하고자 한다.

\section{2. $\mathrm{CK}$ 모형과 관계형 모형}

\section{1. $\mathrm{CK}$ 기본모형과 $\mathrm{CK} 2$ 차함수모형}

Coale과 Guo (1989)는 고연령에 있어서 사망률의 로그증가율은 곰페르츠모형의 경우처럼 상 수(constant)가 아니고 선형적으로 감소한다는 점에 착안하여 사망표의 마감방법을 사용하였다. 고 연령 사망력의 이러한 특징은 실증적으로 여러 논문에서 검증되었으며, Coale과 Kisher (1990)는 각세 별 실증사망표를 마무리하기 위하여 Coale과 Guo (1989)에서 사용한 아래와 같은 Coale과 Kisher방 법(CK모형)을 제안하였다.

Coale과 Kisher방법에서는 두 개의 모수, 즉 곰페르츠 모수 $k_{x}$ 와 최상위 연령, 남자의 110 세의 사 망률 $\left(m_{110}\right)$ 을 1.0 으로, 여자의 110 세의 사망률을 0.8 의 값으로 부여하였다. 이 때 남자의 경우 110 세 이상의 사망자가 없으므로 $m_{110}=1.0$ 으로 설정하는 것은 합리적이라고 하였고, 여자의 경우 $m_{110}$ 을 0.8 로 설정한 것은 110 세에서 남자와 여자의 사망력의 교차를 피하기 위하여 선택하였다.

먼저, 특정연령의 곰페르츠모수 $k_{x}$ (사망률의 로그증가율)를

$$
k_{x}=\ln \left(\frac{m_{x}}{m_{x-1}}\right)=\ln \left(m_{x}\right)-\ln \left(m_{x-1}\right)
$$

라 하고, $x=85$ 라고 하면

$$
m_{x}=m_{84} * \exp \left[\sum_{y=85}^{x} k_{y}\right], \quad x=85,86,87, \ldots
$$


와 같이 되고, $k_{x}$ 가 일정하다면 $\left(k_{x}=k\right)$, 고전 곰페르츠모형이 된다. CK모형에서는 어떤 연령(예: 85 세 $)$ 이상에서, $k_{x}=k_{85}+s *(x-85)$ 와 같이 선형이라고 가정한다. 이 식을 $s$ 에 대하여 풀면

$$
s=-\frac{\left[\ln \left(m_{84} / m_{110}\right)+26 k_{85}\right]}{325}
$$

이 된다. 따라서 연령별 사망률은 다음과 같으며 본 논문에서는 이를 $\mathrm{CK}$ 기본모형이라 부르기로 한다.

$$
m_{x}=m_{84} * \exp \left[\sum_{y=85}^{x}\left(k_{85}+(y-85) * s\right)\right], \quad x=85,86, \ldots
$$

또한, Wilmoth (1995)에서는 이를 다음과 같이 확장하여 제시하였으며 이를 본 논문에서는 CK 2차 함수모형이라 부르기로 한다. 식 (2.4)로부터

$$
m_{x}=m_{84} \exp \left[(x-84) k_{85}+\frac{(x-84)(x-85)}{2} * s\right]
$$

을 얻을 수 있는데, 양변에 로그를 취하면

$$
\ln \left(m_{x}\right)=\ln \left(m_{84}\right)+(x-84) k_{85}+\frac{(x-84)(x-85)}{2} * s+\epsilon_{x}
$$

와 같이 연령 $(x)$ 에 대한 2차함수형태가 된다.

\section{2. 관계형 모형(Relational Model)}

Brass (1971)에서는 두 개의 서로 다른 연령별 사망패턴의 사망률 Logit간에 선형관계가 성립한다 는 가정 하에서 표준인구의 연령별 사망력 Logit과 $t$-연도의 연령별 사망률 Logit간의 선형관계를 다음 과 같이 나타내었다.

$$
\operatorname{Logit}\left(m_{x, t}\right)=\alpha+\beta \cdot \operatorname{Logit}\left(m_{x, s}\right)
$$

여기서 $\operatorname{Logit}\left(m_{x, t}\right)=0.5 \cdot \ln \left(m_{x, t} /\left(1-m_{x, t}\right)\right), m_{x, s}$ 는 표준인구의 연령별 사망률이다.

Himes 등 (1994)에서 제안한 표준인구 사망력표(표준 HPC)는 다양한 국가와 기간동안 관측된 패 턴에 기반하여 고연령층에 대한 전형적인 사망력 패턴을 나타내기 위하여 로지스틱모형을 근간으로 하 여 관계형 모형을 적용하였다.

표준 HPC는 16 개의 고연령 선진국 국가들의 1948-1985년까지의 5년주기의 센서스자료를 중심으 로 45-99세까지의 각세별 사망률을 검토하여 작성하였다. 고려중인 특정 인구에 대한 사망력의 연령 패턴과 가장 근사한 추정방법인 표준 모형과의 선형함수관계

$$
\Psi_{j}(x)=\alpha_{j}+\beta_{j} \Psi_{s}(x)
$$

를 만족하는 변환을 찾는 것이다. 여기서 $\Psi_{j}(x)$ 는 인구 $j$ 에서 $x$ 세의 사망률의 변환이고, $\alpha_{j}, \beta_{j}$ 는 인구 $j$ 에 대한 모수이고, $\Psi_{s}(x)$ 는 표준인구에서 $x$ 세의 사망률의 변환으로, 특정연령 사망률의 Logit변환을 이용하여 표준 인구모형을 구성한다. 


\section{3. 우리나라의 고연령 사망력 추정}

\section{1. 고연령 사망력 추정을 위한 기초자료}

우리나라의 장래 사망력을 추계하기 위해서는 사망력의 감소 및 기대수명의 증가속도를 감안한다 면 최소한 100 세 이상까지의 과거 사망률이 필요하다. 그러나 우리나라의 사망력자료를 보면 실제 고 연령층까지 사망력 예측에 사용하기에는 상당한 한계가 있다.

필요한 연앙사망률(central rate of mortality) 산출을 위해서는 각세별로 신뢰할 수 있는 고연령층 의 연앙인구와 사망자수 자료가 필요하다. 연앙인구는 1970년에서 1995년까지는 각세별 79세까지, 1996년부터 1999년까지는 84세까지, 2000년부터 2010년까지는 99세까지의 자료를 활용할 수 있다. 사망자의 경우는 1970년부터 1999년까지는 각세별로 79세까지, 2000년부터 2010년까지는 89세까지 의 자료를 활용할 수 있다.

이와 같이 고연령 사망력에 대한 시계열자료가 절대적으로 부족하고 특히, 고연령까지 생존하는 사 람들의 수가 적기 때문에 연령층이 높아질수록 랜덤 변동(random fluctuation)현상이 나타난다. 따라서 시계열이 짧고 랜덤 변동이 포함되어 있는 사망력자료를 어떻게 활용하여 고연령층의 사망력을 추정할 것인가가 매우 중요한 문제이다.

\section{2. 고연령 사망력 추정을 위한 모형의 선정}

고연령층 사망력의 연령패턴은 과거에는 곰페르츠곡선 등 전통적으로 다양한 방법들에 의해 젊은 연령층의 사망력자료로부터 외삽(extrapolation)을 기반으로 주로 이루어졌다. 그러나 고연령층의 신 뢰할 수 있는 자료가 부족한 상태에서 젊은 연령층자료를 토대로 고연령층을 추정하는 것에 대한 신뢰 성 자체가 의문시 되었다.

Coale과 Kisher (1990)와 Wilmoth (1995)에서는 연령별 사망률의 로그증가율 $k_{x}$ 가 연령에 따라 변 화한다는 것에 착안한 분석결과가 제시되었다. 사망률의 로그증가율 $k_{x}$ 에 대한 고연령 선진국의 사례 에서 보면 75세에서 85세 사이에서 추세의 변화를 보여주었다.

또한, 많은 연구에서 고연령층의 사망력은 이미 곰페르츠곡선의 패턴을 따르지 않는다는 연구결과 를 발표하였으며, 특히, Boleslawski와 Tableau (2002) 등에서는 인구의 고연령층 확장을 위한 추정식에 서 곰페르츠 등 전통적인 모형의 한계를 제시하기도 하였다. Buettner (2002)는 수리적 함수의 경우 그 결과는 당연히 실질 사망력이 사용한 함수형태와 일치할 때 만족스러운 결과를 가져다준다는 점을 지 적하였다.

1997년 UN에서 연령별 사망력을 고연령층까지 확장하기 위해 Himes 등 (1994)에서 제시된 표준 고연령 사망력 모형(표준 HPC모형), Heligman-Pollard (1980) 사망모형의 고연령부문, Coale과 Kisher (1990)에서 제시한 사망력 마무리방법을 보다 자세히 검토한 바 있다. 이 중에서 표준 HPC모형을 사 용할 것을 추천하였는데, 이는 신뢰할 수 있는 다양한 인구에 대한 고연령 사망력 패턴으로부터 도출되 었기 때문이었다. 그러나 고연령의 사망률이 랜덤변동에 의해 영향을 받기 때문에 95 세 이상의 표준 HPC는 Heligman과 Pollard가 제시한 고연령층부문을 사용하여 도출된 사망률로 대체하고, 고연령층 의 서로 다른 생명표간의 사망력이 교차하는 것을 피하기 위하여 $\mathrm{CK}$ 방법을 생명표의 마무리단계에 적 용하였다.

본 논문에서는 여러 연구결과, 우리나라의 연령별 사망률 자료의 짧은 시계열과 신뢰할 수 있는 고 연령층에 대한 자료 부족 등의 현실자료의 한계를 감안할 때 수리적 방정식의 많은 모수 추정보다는 경 험적인 표준 사망률자료를 토대로 고연령층에 대한 접근이 보다 타당하다는 판단 하에 관계형 모형을 고려하되, 관계형 모형 적용을 위한 표준 사망률 또한 모형 설계시 고연령층에 대한 경험적 사망률을 최대한 반영한 $\mathrm{CK}$ 모형을 검토하게 되었다. 


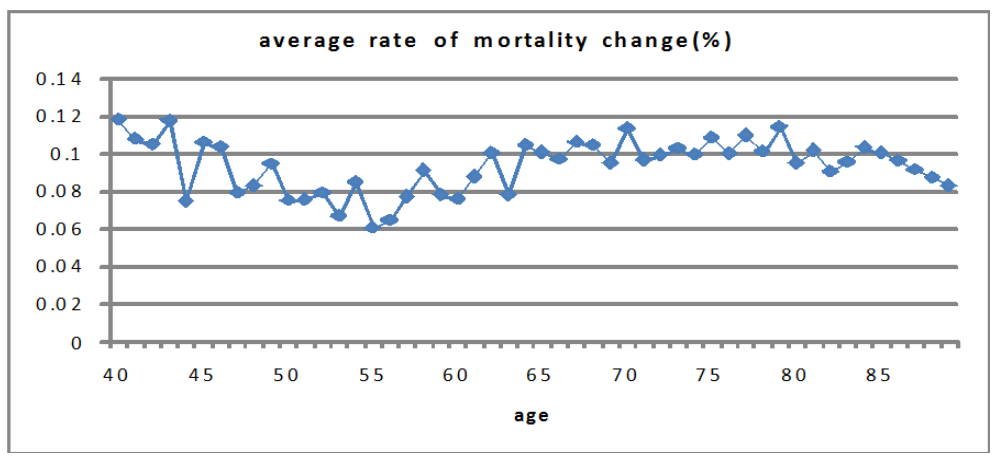

Figure 1: Average rate of mortality change with age, $k_{x}$ (male)

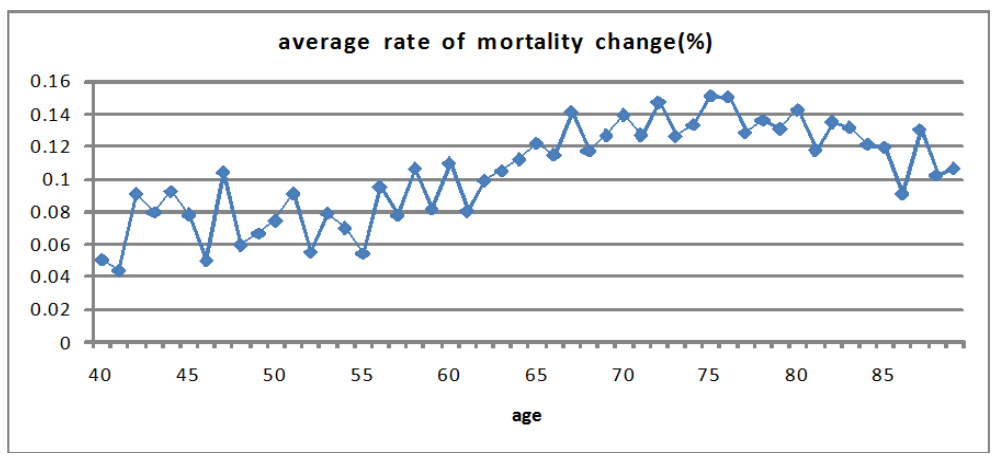

Figure 2: Average rate of mortality change with age, $k_{x}$ (female)

우선, $\mathrm{CK}$ 모형이 관계형 모형에서의 경험적 표준 사망률을 적정하게 추정이 가능한지를 알아보기 위해서 우리나라의 연령별 사망력의 추세가 고연령으로 가면서 어떤 변화가 있는지를 Coale과 Kisher (1990)와 Wilmoth (1995)에서 검토한 사망률의 로그증가율의 추세를 살펴보았다. 우리나라의 남녀 별/연령별 사망률의 로그 증가율의 추세를 살펴보기 위하여 고연령층에, 특히 75 세 이상 충분한 자료 에 대한 분석이 선행되어야 하는데 우리나라의 경우 이러한 분석이 가능한 자료는 대략 2001-2010년 이다. 따라서 이러한 10 년간 자료를 통해서 남녀별/연령별 사망률의 로그증가율 변화추세를 살펴보 면, Figure 1은 남자의 10년 평균 사망률의 로그증가율 추이로서 대략적으로 40-55세까지 감소, 5580 세 전후까지는 증가, 80 세 전후부터 소폭의 감소추세를 보여 주고 있다. Figure 2 는 여자인 경우로서 45-55세까지는 감소, 55세에서 75세까지 증가추세를 보이다가 이후 뚜렷한 증가율 감소추세를 보이는 것을 알 수 있다. 이러한 추세를 볼 때 우리나라의 경우 고연령층의 사망률을 추정하기 위해서는 적어 도 80세 이상의 자료를 토대로 모형을 적합할 필요가 있다.

즉, 80 세 이전까지의 자료만을 사용하여 사망력을 외삽하게 되면 80세 이상의 고연령층에 대한 변 화추세를 제대로 반영할 수 없게 되는데 2001 년부터 10 년간의 자료를 이용하게 되면 다소 시계열이 짧 은 한계는 있지만 80 세 이상의 고연령층의 추세변화를 반영하여 사망력 추정이 가능하고 특히 CK모형 을 적용하여 고연령층 추정하는 이론적인 근거가 명확하다고 볼 수 있다.

이상을 종합하여 본 논문에서는 $\mathrm{CK}$ 모형을 활용하여 고연령 사망력을 추정하고 추정한 고연령층 사망력자료의 추세를 최대한 반영하기 위하여 2001-2010년까지의 10년간의 110세까지의 각세별 산 술평균을 관계형 모형에 적용할 각세별 표준 사망률로 하여 관계형 모형에 적용하여 1970 년까지의 고 연령층의 사망력을 추정하였다. 
Table 1: Comparison of RMSE and MAPE by fitting periods and models

\begin{tabular}{|c|c|c|c|c|}
\hline & starting age & 70 & 75 & 80 \\
\hline \multirow{4}{*}{$\begin{array}{c}\max \text { age }=110 \\
m_{x}=1.0\end{array}$} & RMSE(M1) & 0.020177 & 0.023515 & 0.018795 \\
\hline & RMSE(M2) & 0.014025 & 0.017526 & 0.016374 \\
\hline & MAPE(M1) & 0.141420 & 0.143824 & 0.101650 \\
\hline & MAPE(M2) & 0.107124 & 0.114184 & 0.089936 \\
\hline \multirow{4}{*}{$\begin{array}{c}\max \text { age }=120 \\
m_{x}=1.0\end{array}$} & RMSE(M1) & 0.022082 & 0.025575 & 0.020334 \\
\hline & RMSE(M2) & 0.015922 & 0.019593 & 0.018017 \\
\hline & MAPE(M1) & 0.148873 & 0.153840 & 0.108406 \\
\hline & MAPE(M2) & 0.113729 & 0.124425 & 0.097084 \\
\hline \multirow{4}{*}{$\begin{array}{c}\max \text { age }=110 \\
m_{x}=0.8\end{array}$} & RMSE(M1) & 0.015936 & 0.011219 & 0.024562 \\
\hline & RMSE(M2) & 0.010885 & 0.008161 & 0.017757 \\
\hline & MAPE(M1) & 0.150358 & 0.094011 & 0.179706 \\
\hline & MAPE(M2) & 0.112866 & 0.072601 & 0.137144 \\
\hline \multirow{4}{*}{$\begin{array}{c}\max \text { age }=120 \\
m_{x}=0.8\end{array}$} & RMSE(M1) & 0.018555 & 0.011305 & 0.026463 \\
\hline & RMSE(M2) & 0.016256 & 0.010687 & 0.018988 \\
\hline & MAPE(M1) & 0.166803 & 0.094506 & 0.190692 \\
\hline & MAPE(M2) & 0.145950 & 0.084617 & 0.143469 \\
\hline
\end{tabular}

3.3. 추정결과

\subsection{1. 연령별 표준 사망률의 추정}

Brass (1971)와 Himes 등 (1994) 등에서 제시한 관계형 모형을 적용하기 위해서는 연령별 표준 사 망률을 구해야 한다. 이를 위하여 75세 이상의 고연령층 사망력자료가 있는 2001년부터 2010년까지 의 자료를 활용하였다.

모형은 2.1절에서 설명한 바와 같이 $\mathrm{CK}$ 기본모형(M1)과 $\mathrm{CK} 2$ 차함수모형 $\left[\ln \left(m_{x}\right)=\alpha+\beta x+\right.$ $\left.\gamma x^{2}\right](\mathrm{M} 2)$ 으로 나누어서 검토하고, 시작연령 $x_{0}$ 을 Figure 1, Figure 2를 토대로 70-80세까지 5세 간격으 로 하고, 최고연령을 110 세와 120 세로 나누고, 남자의 사망률은 1.0 , 여자의 사망률은 0.8 을 가정하였 다. 여기서 최고연령을 110 세와 120 세로 주어진 것은 Coale과 Kisher방법을 제시할 당시 사망자가 없 는 연령인 110 세를 우선 고려하되, 우리나라의 고령화속도를 감안하여 120 세까지의 연장가능여부를 검토하였다.

추정결과를 Table 1의 RMSE와 MAPE를 기준으로 보면 모형의 경우 남녀 모두 CK 2차함수모 형의 적합력이 우수하였으며, 추정을 위한 시작연령은 남자는 RMSE가 70세 이후에서 가장 작으나 MAPE는 80세 이후가 가장 작은 것으로 나타나 Figure 1에서 추세의 전환점이 80세인 점을 고려하여 80 세 이후를 선택하였다. 여자는 75세 이후가 적합력이 우수하였고, Figure 2에서도 동일한 결과를 볼 수 있다. 최고연령도 120 세보다는 110 세로 설정하는 것이 타당한 것으로 나타났다.

추정결과 연도별 실측값과 추정값을 비교하면 Figure 3 과 Figure 4와 같고, 각세별 표준 사망률을 산출하면 Figure 5와 같다.

\subsection{2. 관계형 모형에 의한 과거자료 보완 및 연장}

Himes 등 (1994) 등에서 제시한 관계형 모형은 $\Psi_{j}(x)=\alpha_{j}+\beta_{j} \Psi_{s}(x)$ 와 같은 관계로 나타낼 수 있으며 이를 통해 고연령 사망률자료를 추정하게 되는데, 이 중 $\Psi_{j}(x), \Psi_{s}(x)$ 를 사망률의 Logit변환 을 사용하였다. 본 논문에서는 우리나라 자료를 통하여 최적의 관계형 모형을 적용하기 위하여 $\Psi_{j}(x)$, $\Psi_{s}(x)$ 의 값을 ‘사망률을 변환없이 적용할 것인지(무변환)', ' $\mathrm{LN}$ 변환', 'Logit변환'을 적용할 것인지 여 부를 먼저 파악하고자 한다. 


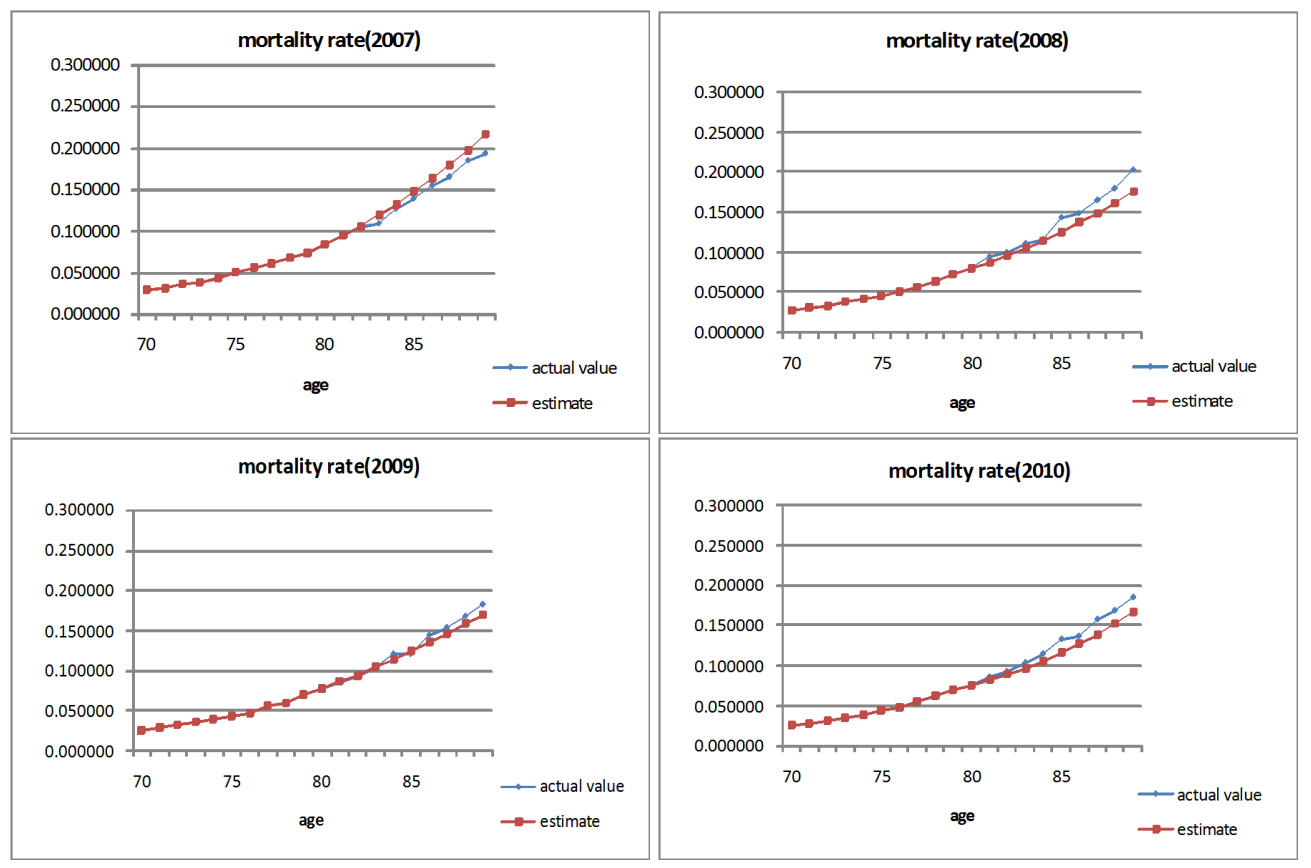

Figure 3: Comparison of actual value and estimate(male)
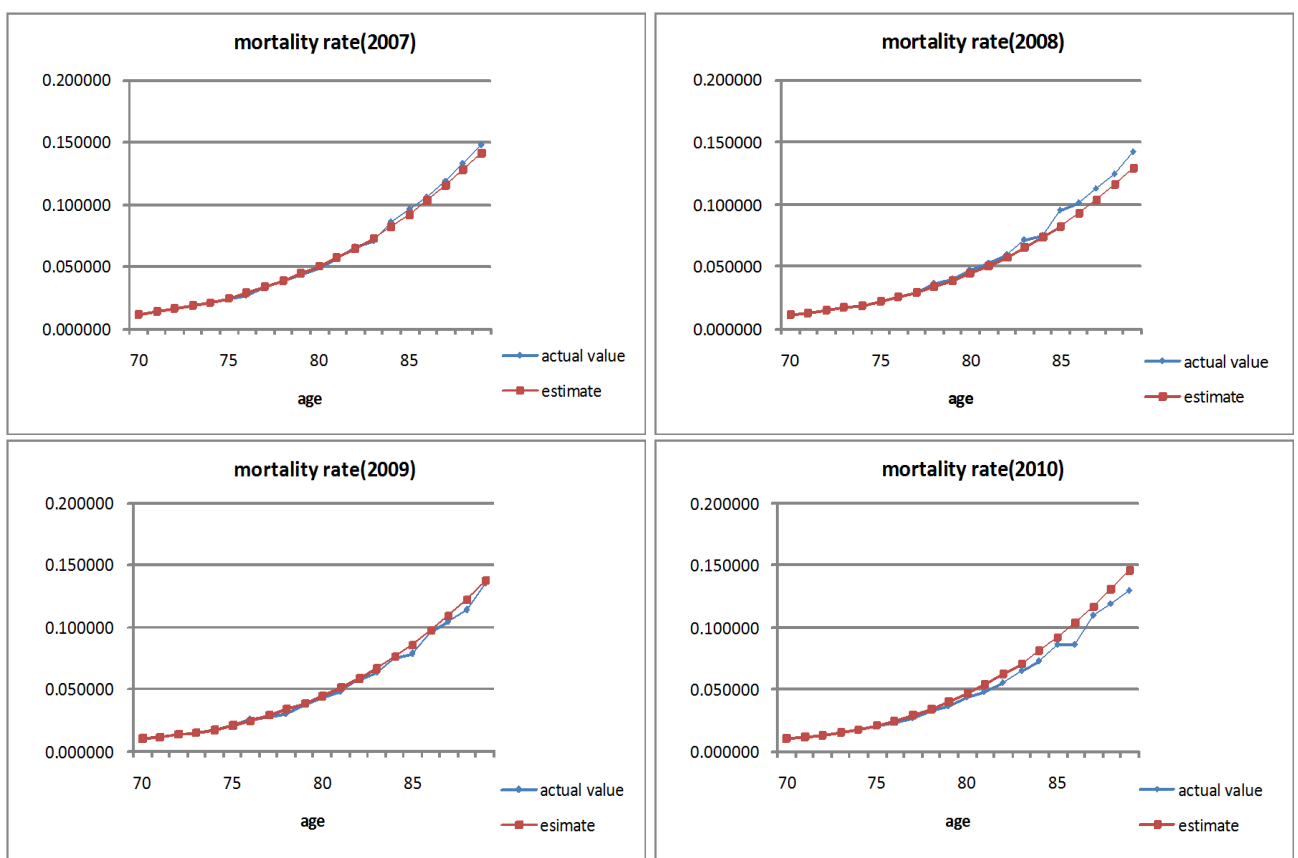

Figure 4: Comparison of actual value and estimate(female) 


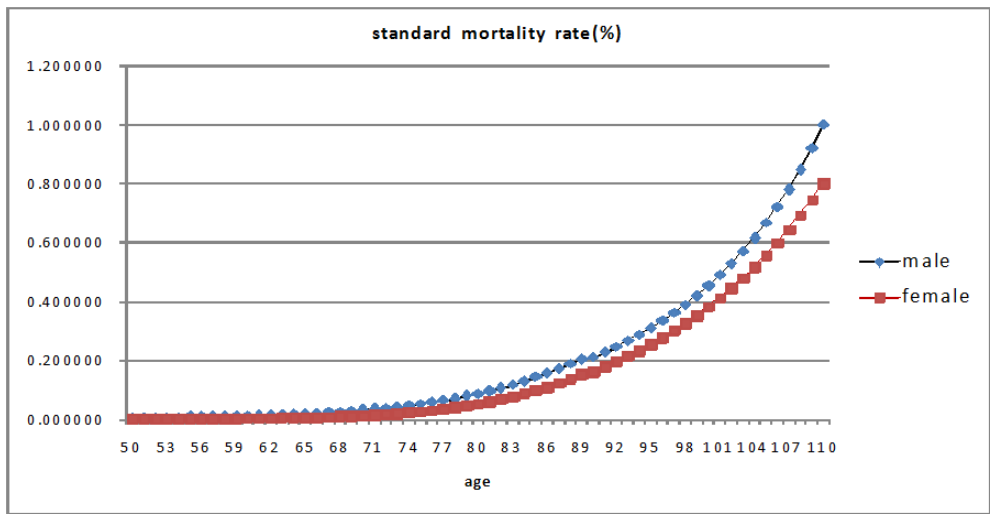

Figure 5: Standard mortality rate estimated by CK model

Table 2: Coefficient of determination $\left(R^{2}\right)$ by the type of transformation

\begin{tabular}{ccccccc}
\hline \hline (male) age & 50 \& over & 55 \& over & 60 \& over & 65 \& over & 70 \& over & 75 \& over \\
\hline No transformation & $\mathbf{0 . 9 9 0 9 9}$ & 0.99034 & 0.98851 & 0.98384 & 0.97387 & 0.92901 \\
LN transformation & $\mathbf{0 . 9 9 4 7 6}$ & 0.99440 & 0.99195 & 0.98637 & 0.97672 & 0.93242 \\
Logit transformation & $\mathbf{0 . 9 9 5 0 2}$ & 0.99435 & 0.99155 & 0.98589 & 0.97639 & 0.93212 \\
\hline & & & & & \\
\hline (female) age & 50 \& over & 55 \& over & 60 \& over & 65 \& over & 70 \& over & $75 \&$ over \\
\hline No transformation & 0.97843 & 0.98093 & $\mathbf{0 . 9 8 2 8 7}$ & 0.98235 & 0.97528 & 0.93626 \\
LN transformation & $\mathbf{0 . 9 9 5 4 8}$ & 0.99489 & 0.99310 & 0.99032 & 0.97810 & 0.94064 \\
Logit transformation & $\mathbf{0 . 9 9 5 6 2}$ & 0.99496 & 0.99310 & 0.99023 & 0.97799 & 0.94070 \\
\hline \hline
\end{tabular}

먼저, 3 가지 변환 중 가장 적합력이 뛰어난 모형을 찾기 위하여 각 변환별로 표준사망률 $\Psi_{s}(x)$ 을 구 하고 이에 대응하는 각세별 자료 $\Psi_{j}(x)$ 를 구한 후 몇 세 이후 자료들간의 결정계수 $\left(R^{2}\right)$ 가 우수한지 파 악하기 위하여 모의실험을 실시하였다. 그 결과를 보면 Table 2에서와 같이 Logit변환이 남녀 모두 가 장 우수한 것으로 나타났다. 또한 50세 이후 사망력자료를 이용할 때 설명력이 가장 우수하다는 것을 알 수 있다. 따라서 본 논문에서는 각 년도의 50 세 이상의 사망력자료를 토대로 $\alpha_{j}, \beta_{j}$ 의 추정값을 구하 고, 이를 토대로 50 세 이상 110 세까지의 사망력에 대한 각 년도의 각세별 사망률을 추정하였다.

\subsection{3. 사망확률 및 기대여명 산출}

확장한 1970-2010년의 사망력자료로 기대여명을 작성하기 위해서 사망확률로 변환하여야 하는 데, 본 논문에서는 Thatcher 등 (1999) 등에서 도출한 사망확률 $(q)$ 와 연앙사망률 $(m)$ 과의 관계인 $q_{x} \simeq$ $1-e^{-m_{x}}$ 을 사용하였다.

또한, 이렇게 산출한 사망확률을 통해 생명표를 작성할 때 생명표의 안정적 결과를 얻기 위하여 보 정작업을 실시하였다. 보정작업은 일반적으로 자료의 적합도(fitness)와 평활도(smoothing)를 사용하 여 보정식의 적정성을 파악하게 되는데 본 논문에서는 통계청에서 사용하고 있는 Greville (1881)에서 제시한 Greville 9차항 보정방법을 적용하였다. 이러한 사망확률을 이용하여 통계청의 생명표 작성방 법에 따라 각세별 생존자수, 사망자수, 정지인구 및 총 생존년수를 구하여 최종적으로 산출한 2010년 도의 각세별 기대여명은 Figure 6과 같고, 통계청에서 발표한 생명표와 본 논문에서 추정값과의 비교결 과는 Figure 7 과 같다. 


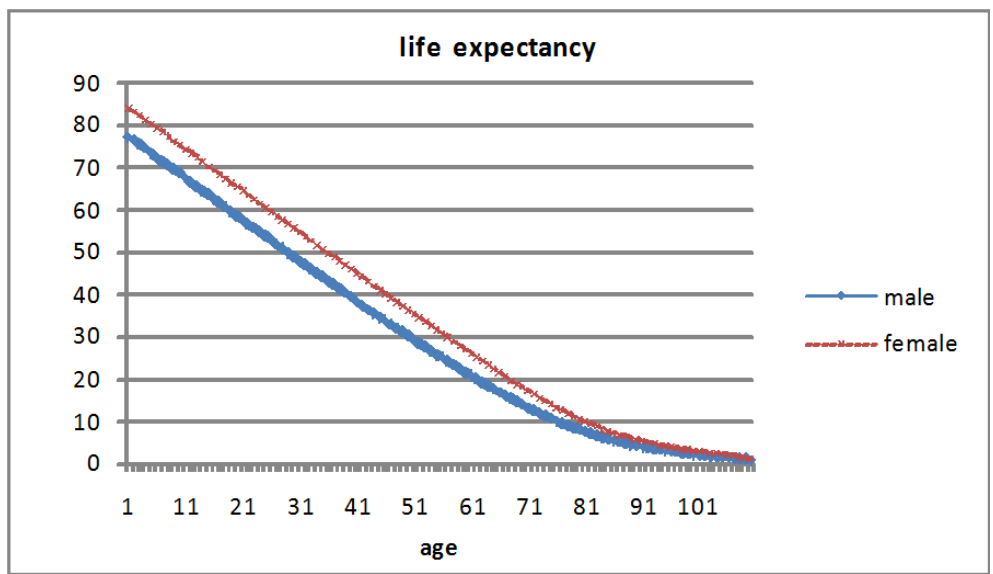

Figure 6: Life expectancy by age(2010)
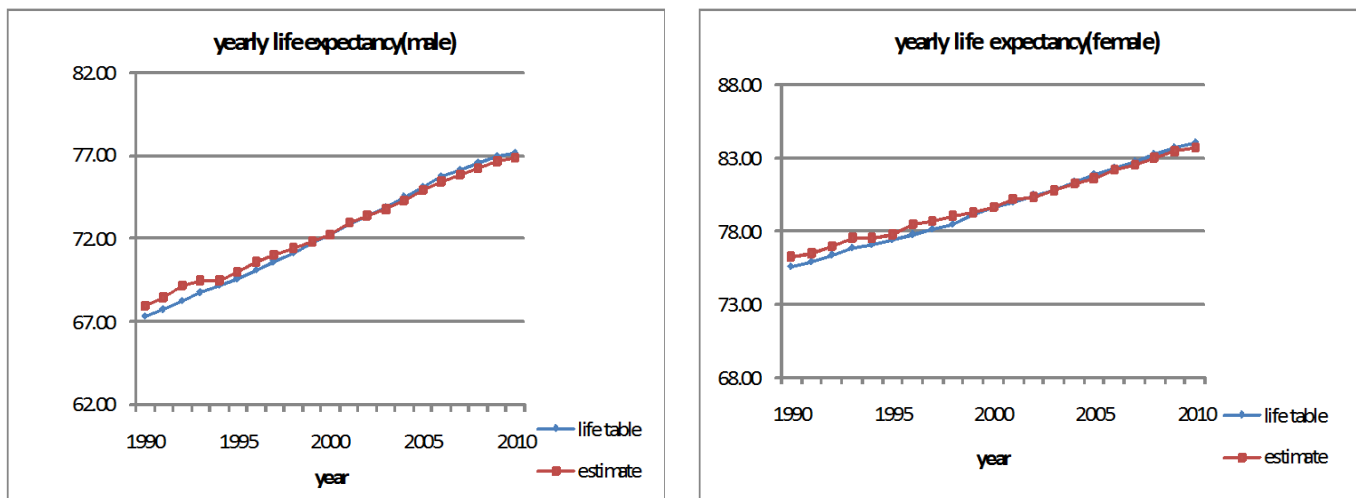

Figure 7: Comparison of life table and estimate

\section{4. 결론}

장래 사망력 추정을 위한 고연령 사망력 추정방법은 국가별 특성 및 시계열자료의 신뢰성 등을 고 려한 모형선정이 무엇보다도 중요하다. 단순히 기존에 제시한 여러 모형에 대한 통계적 적합만으로 판 단한다면 우리나라의 사망력 특성을 정확하게 반영하기에는 한계가 있다. 즉, Thatcher 등 (1999) 등 에서 볼 수 있듯이 여러 모형을 대상으로 통계적 유의성을 비교해 보면 상당수 수리적 모형은 80-95세 까지는 매우 유사한 결과를 얻을 수 있다. 그러나 95세 이상에서부터는 모형별로 큰 차이를 보여준다. 또한 과거에는 사망력이 시간에 따른 모양이나 변화패턴 등 뚜렷한 지역적 특징을 나타냈다. 이러한 이유로 여러 종류의 모형생명표가 만들어지고 적절하게 사용되어졌다. 그러나 미래에 있어서 모든 국 가들이 고연령국가로 전환될 것으로 보여 사망력이나 변화패턴은 궁극적으로 하나 또는 매우 적은 수 의 특성패턴에 수렴하거나 근본적인 변화가 지속될 것인지 여부와 관련된다. 우리나라의 경우도 최근 의 고령화 추세를 보면 평균수명에서 이미 고령화 선진국수준에 근접했고, 향후에도 이러한 추세가 지 속될 것으로 보인다. 본 논문에서는 고연령 사망력 추정을 위해 CK모형의 2차함수 모형을 사용하였는 데 이는 기본적으로 우리나라 고연령 사망력 패턴을 잘 대변해 주고 있음을 알 수 있다. 따라서 이를 표 준 사망력으로 하여 과거자료를 관계형 모형으로 보완함으로써 향후 장래 사망력 추계의 좋은 모델이 
될 것으로 본다. 향후 우리나라의 고연령층에 대한 과거자료를 보다 체계적으로 정비하고, CK모형 적 용을 2차함수로 그치지 말고 다차함수로의 확장 또한 시도할 필요가 있다.

\section{References}

Baek, J. S. and Jeong, M. O. (2012). Study on Mortality Models for Population Projection, Statistical Research Institute.

Boleslawski, L. and Tableau, E. (2002). Comparing theoretical age patterns of mortality beyond the age of 80 in forecasting mortality in developed countries, European Association for Population Studies, Kluwer Academic Publishers, 127-155.

Brass, W. (1971). On Scale of Mortality, Biological Aspects of Demography, Taylor \& Francis, London.

Buettner, T. (2002). Approaches and experience in projecting mortality patterns for the oldest-old, North American Actuarial Journal, 6, 14-29.

Coale, A. and Demeny, D. (1966). Regional Model Life Tables and Stable Populations, Prinston University Press, Prinston.

Coale, A. and Guo, G. (1989). Revised regional model life tables at very low levels of mortality, Population Index, 55, 613-643.

Coale, A. J. and Kisher, E. E. (1990). Defects in data on old-age mortality in the United States: New procedures for calculating mortality schedules and life tables at the highest ages, Asian and Pacific Population Forum, 4, 1-32.

Gompertz, B. (1825). On the nature of the function expressive of the law of human mortality, and on a new mode of determining the value of life contingencies, Philosophical Transactions of Royal Society(Series A), 115, 513-583.

Greville, T. N. E. (1981). Moving-weighting-average smoothing extended to the extremities of the data, Scandinavian Actuarial Journal, 39-55.

Heligman, L. and Pollard, J. H. (1980). The age pattern of mortality, Journal of the Institute of Acuaries, 107, 49-80.

Himes, C. L., Preston, S. H. and Condran, G. A. (1994). A relational model of mortality at older ages in low mortality countries, Population Studies, 48, 269-291.

Kim, S. Y., Kim, K. W. and Park, Y. S. (2011). An extension of mortality for oldest-Old age in Korea, Survey Research, 12, 1-26.

Statistics Korea. Life tables for Korea, 2001-2010.

Thatcher, A. R., Kannisto, V. and Vaupel, J. W. (1999). The Force of Mortality at Ages 80 to 120 in Monographs on Population Aging 5, Odense University Press.

United Nations (1982). Model Life Tables for Developing Countries, United Nations, New York.

Wilmoth, J. R. (1995). Are mortality rates falling at extreme high ages? An investigation based on a model proposed by Coale and Kisher, Population Studies, 49, 281-295. 